\title{
Sex ratios and spatial structure of the dioecious tree Torreya nucifera in Jeju Island, Korea
}

\author{
Hyesoon Kang ${ }^{1, *}$ and Sookyung Shin ${ }^{1,2}$ \\ ${ }^{1}$ School of Biological Science and Chemistry, Sungshin Women's University, Seoul 142-732, Korea \\ ${ }^{2}$ Present address: Division of Forest Genetic Resources, Korea Forest Research Institute, Suwon 441-847, Korea
}

\begin{abstract}
The sex ratio and spatial structure of different sexes are major components that affect the reproductive success and population persistence of dioecious plants. The differential reproductive costs between male and female plants are often believed to cause a biased sex ratio and spatial segregation of the sexes through slower growth and/or lower female survivorship. In this study, we examined the sex ratio and spatial structure of one population of Torreya nucifera trees in Jeju Island, Korea. We also tested the effects of the current tending actions in relation to tree vitality. At the population level, the sex ratio of the 2,861 trees was significantly biased toward males; however, it also showed considerable variation among different diameter at breast height classes and across habitats according to terrain level (from upper to lower). In 1999, before tree management (tending) began, among the ecological traits examined, only climber coverage correlated with tree vitality. Intensive tending such as climber removal since 1999 clearly enhanced the vitality of the majority of trees, but its effects were more conspicuous in medium-sized trees than in small ones, in upper terrain trees than those in other terrains, and in females than in males. Both male tree domination in small and large trees and tending effects on females are likely to reflect the effects of female reproductive costs regarding growth and/or survivorship. Spatial segregation between males and females was not observed in T. nucifera. Habitat heterogeneity created by the forest's rocky ground and its implications regarding sex ratios and spatial structure require further studies.
\end{abstract}

Key words: dioecy, sex ratio, spatial pattern, tending, Torreya nucifera

\section{INTRODUCTION}

The sex ratio of dioecious plants is an important factor in the reproductive success of male and female plants and, furthermore, in population and species persistence (Renner and Ricklefs 1995). If the reproductive costs of male and female plants are equivalent, frequency-dependent selection should result in a 1:1 sex ratio (Fisher 1930). Mixed patterns have been reported, though malebiased sex ratios (Opler and Bawa 1978, Ornduff 1985, Sakai 1990, Allen and Antos 1993) are more common than female-biased ones (Crawford and Balfour 1990, Ueno et al. 2007) or 1:1 sex ratios (Ortiz et al. 1998, Schmidt 2008). Male-biased sex ratios are generally ascribed to the effects of higher reproductive costs of females than males. Many authors have inferred higher female reproductive costs from slower growth (Obeso et al. 1998, Nuñez et al. 2008), delayed or less frequent flowering and fruiting (Armstrong and Irvine 1989, Thomas and LaFrankie 1993), and/or higher mortality (Lloyd and Webb 1977, Barrett et al. 2010). Differential growth and/or survivorship between male and female plants can generate age- or

\section{Open Access http://dx.doi.org/10.5141/JEFB.2012.015}

This is an Open Access article distributed under the terms of the Creative Commons Attribution Non-Commercial License (http://creativecommons org/licenses/by-nc/3.0/) which permits unrestricted non-commercial use distribution, and reproduction in any medium, provided the original work is properly cited.
Received 05 March 2012, Accepted 02 April 2012

*Corresponding Author

E-mail: hkang@sungshin.ac.kr

Tel: +82-2-920-7475 
stage-specific sex ratios, especially for long-living plants. However, different species adapt different mechanisms to compensate for the females' higher reproductive costs (Queenborough et al. 2007).

The sex-differential reproductive cost of dioecious plants can result in sex-dependent spatial segregation (SSS) (Bawa and Opler 1977, Bierzychudek and Eckhart 1988, Houle and Duchesne 1999). Females subjected to resource limitations due to high reproductive costs tend to be common in more favorable or less stressful conditions in terms of elevation (Nuñez et al. 2008), water availability (Ortiz et al. 2002), and/or soil fertility (Lawton and Cothran 2000). For example, female Acer negundo (Freeman et al. 1976), Populus tremuloides (Grant and Mitton 1979), and Salix arctica (Dawson and Bliss 1989) are found in sites with a relatively greater amount of moisture. However, conflicting results for SSS have recently been documented in diverse plants (Osunkoya 1999, Ueno et al 2007, Schmidt 2008, Gao et al. 2009, Forero-Montaña et al. 2010). Due to the fact that the distance and distribution between male and female plants influences the level of outcrossing, and consequently seed production (Bawa and Opler 1977), SSS is one of the major components determining dioecious plants' fitness levels.

In this study, we examined the sex ratio and spatial structure of the dioecious Torreya nucifera, a member of the tertiary relict Torreya (Sargent 1896 cited in Kim 1985, Donoghue et al. 2001, Milne and Abbott 2002) that occurs only in certain parts of Korea and Japan. Torreya nucifera Forest (Torreya Forest hereafter) in Korea's Jeju Island is known as the largest $(N=2,861)$ and oldest (mostly 200400 years old; max. $~ 880$ years old) population of $T$. nucifera in the world. Since this forest is historically believed to be a natural forest in which anthropogenic activities have been controlled for several hundreds of years (Kim 1985, Shin et al. 2010), it offers a good opportunity to examine sex ratio patterns across size, age groups, and spatial structure. The T. nucifera trees examined in this study were located on the rocky terrain called "Gotjawal," which is composed of 'a'a lava and pahoehoe lava (Song 2000), and the forest upon it is called Gotjawal Forest. It is characterized by its high diversity of plant and animal species and rapid rain water filtration to ground aquifers (Song et al. 2007). Although observations such as lack of seedlings and exotic species invasions (Korea Tree Health Association [KTHA] 1999, Lee 2005, 2009) can be signs of forest degeneration, to date, only limited studies on vegetation (KTHA 1999, Lee 2005, 2009, Shin et al. 2010) and population genetics (Kim and Kwon 1989, Kang 1993, Hong et al. 2000) have been conducted.
To our knowledge, the first quantitative survey sexing T. nucifera trees in Torreya Forest in Jeju Island was conducted in 1971 (Bukjeju-gun 1971), and it showed female dominance (female, 1,438 vs. male, 1,139). However, more recent surveys (KTHA 1999, Lee 2009) assumed a 1:1 ratio at the population level, but did not employ any statistical testing or consideration of ecological traits such as plant size or sex. In an attempt to delay or reverse the decline of the Torreya population, diverse tending actions, such as climber and competing broadleaf tree removal, and surgery on weak trees, have been employed since 1999. The forest's appearance seems to have improved; however, whether the tending effects are the same among individual trees with different ecological traits, e.g., between males and females, has not yet been examined. Gotjawal Forest tends to be infertile due to thin soils, and its rockiness creates a high level of microhabitat heterogeneity. Thus, if habitat selection occurs differently between the sexes, it may be possible to observe spatial structure or clumping tree patterns between the sexes. Therefore, in this study, we address the following questions: 1) Is the sex ratio of $T$. nucifera 1:1;2) Are there differences in ecological traits such as size and vitality between male and female trees as well as among different habitats within the forest; 3) Did the tending over the past ten years affect the trees' vitalities; and 4) Are male and female trees spatially segregated?

\section{MATERIALS AND METHODS}

\section{Species and study site}

Torreya nucifera S. et Z. (Taxaceae) is a needleleaf dioecious species. It is pollinated in April, and green fleshy aril-covered seeds mature in the fall one year after pollination (Lee 2003). Various parts of this tree have traditionally been used, for example, its wood is used for furniture and its seeds are used for anthelmintic and Oriental medicines as well as for oil. Similarly to other species of the genus Torreya that exhibit a disjunct distribution, $T$. nucifera is currently distributed in parts of Korea and Japan only. In Korea, it occurs below $35^{\circ} 10^{\prime} \mathrm{N}$ in eight sites (three sites with a large individual tree and five stands) in southern Korea, including one in Jeju Island, all of which are designated natural monuments. This study was conducted in Torreya Forest (Natural monument No. 374) in Pyungdae-ri, Jeju Island $\left(33^{\circ} 29^{\prime} \mathrm{N}, 126^{\circ} 48^{\prime} \mathrm{E}\right)$. This forest (44.8 ha area and $143 \mathrm{~m}$ mean a.s.l.) is located between two small volcanoes, the Darangshioreum (382.4 m a.s.l.) 

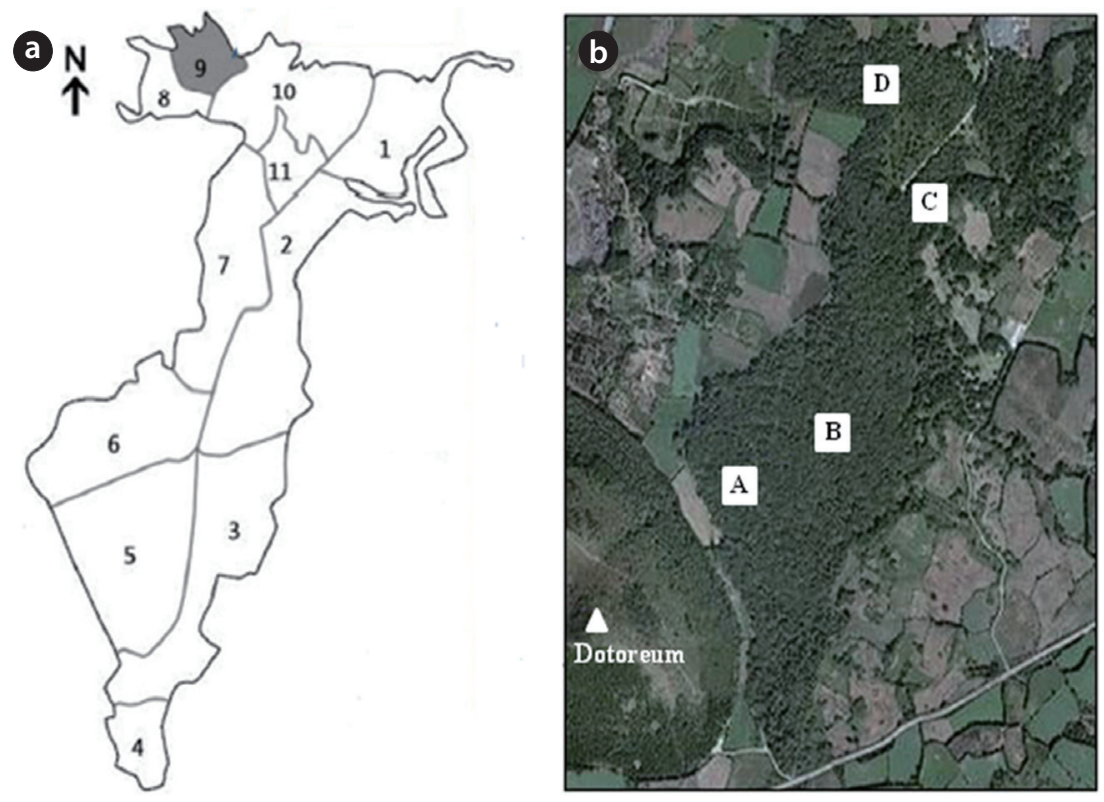

Fig. 1. (a) Map of Torreya nucifera Forest in Jeju Island (adapted from Lee 2009). Numbers indicate the eleven managed plots defined by trails within the forest. All plots except for Plot 9 have been tended since 1999. (b) Location of four quadrats $(50 \times 50 \mathrm{~m})$ established in 2010.

and the Dotoreum (a volcano near the southern end of the population; $284.2 \mathrm{~m}$ a.s.l.), and it extends $1.4 \mathrm{~km}$ northward with a width of $0.6 \mathrm{~km}$. According to data from a weather station close to the forest, in 2001 to 2010, the mean monthly temperature ranged from $5.7^{\circ} \mathrm{C}$ in January to $27.2^{\circ} \mathrm{C}$ in August (annual mean temperature, $15.9^{\circ} \mathrm{C}$ ), the mean annual precipitation was $1,474.9 \mathrm{~mm}$ with a peak in August $(304.4 \mathrm{~mm})$, and the mean annual wind speed was $4.0 \mathrm{~m} / \mathrm{s}$ (Korea Meteorological Administration 2011). This forest is renowned for its high species diversity: in addition to $T$. nucifera $(2,861$ trees $\geq 6 \mathrm{~cm}$ diameter at breast height [dbh]), 230 plant species of 187 genera and 83 families and 208 insect species of 62 families are present (Lee 2009).

\section{Data collection and analyses}

During the quantitative survey in 1999 (KTHA 1999), all trees $\geq 6 \mathrm{~cm}$ dbh were tagged and their ecological traits (size [dbh and height], sex, vitality, climber coverage, bark hole area, stripped bark area, number of competing trees, number of shading branches) were recorded. In a later study (Lee 2009), the tagged trees' sizes and vitalities were re-examined. These data were combined into a database. The 1999 data and 2009 data each contained 2,878 trees (male, 1,507 vs. female, 1,371), and 2,861 trees (male, 1,498 vs. female, 1,363 ). These data indicated that 17 trees died between 1999 and 2009. The trees' vitalities were classified into four categories (healthy, moderate, weak, and very weak) depending on their overall conditions, including factors such as leaf amount, leaf color, and trunk damage (KTHA 1999). Climber coverage was classified into four levels: severe, $\geq 60 \%$ coverage; middle, $40-60 \%$; little, $<40 \%$; and none, $0 \%$. "Bark hole area" indicates the hole area in the trunk $\left(\mathrm{m}^{2}\right)$; "stripped bark area" represents the damaged truck area $\left(\mathrm{m}^{2}\right)$; "number of competing trees" is the number of trees potentially competing with each T. nucifera tree; and "number of shading branches" is the number of branches competing for light. Since dbh and height were closely correlated in preliminary analyses (1999, $r=0.70, N=2,878 ; 2009, r=0.69, N=2,861 ; P<$ 0.0001 for both), dbh was used as the tree size indicator.

Ten of eleven plots of Torreya Forest divided by trails (total area, $42.3 \mathrm{ha}$ ) were included in this study because only Pinus thunbergii and broadleaf trees were present in Plot 11 (Fig. 1a). The ten plots showed a slight elevation gradient according to the north-south axis: Plot 5 next to the Dotoreum in the southern end of the population was higher in elevation than Plot 9 at the north end (154 m a.s.l. vs. $128 \mathrm{~m}$ a.s.l.). Thus, we reclassified the ten plots into three habitats according to elevation gradient: Habitat I near Dotoreum is higher in elevation (Plots 3, 4, 5: $149.0 \mathrm{~m}$ mean a.s.l.) than Habitat III, which is farthest from Dotoreum (Plots 1, 8, 9, 10: $129.5 \mathrm{~m}$ mean a.s.l.), while Habitat II is in between (Plots 2, 6, 7: 141.7 m mean a.s.l.). 
Sex ratios in 1999 and 2009 were obtained by the number of male trees divided by the sum of male and female trees for each year. The chi-square test was used to confirm the unbiased sex ratio for each habitat (ten plots and three habitats). One-way ANOVA was used to examine the difference in dbh between habitats or sexes. Two-way ANOVA was subsequently used to test the simultaneous effects of habitat and sex. Annual dbh growth rates were obtained by subtracting the $1999 \mathrm{dbh}$ from the $2009 \mathrm{dbh}$ and then dividing it by 10. Two-way ANOVA was employed to test the effects of habitat and sex on annual growth rates. Because a number of $T$. nucifera trees were covered with climbing or epiphytic plants in 1999, individuals with suspicious dbh measurements were excluded from the analyses. Specifically, since mean annual dbh growth is $1.0 \mathrm{~mm}$ (Lee 2009), analyses were conducted separately for three groups of trees with annual dbh growth rates of $\leq 10 \mathrm{~mm}, \leq 20 \mathrm{~mm}$, and $\leq 30 \mathrm{~mm}$. Spearman rank correlation analyses were used to examine whether the relationships among vitality, climber coverage, areas of bark holes, areas of damaged trunks, the number of competing trees, and the number of shading branches differed between male and female trees. After 1999, all plots except for Plot 9 were tended, e.g., logging of competing trees or removal of climbing plants. The associations between vitality (1999 and 2009) and each of the ecological traits (dbh [3 classes: $<30 \mathrm{~cm}, 30-60 \mathrm{~cm}, \geq 60 \mathrm{~cm}$ ], habitat, sex, and tending) were tested using two-way contingency table analyses. The non-tended plot was excluded from these analyses. After ten years of tending, three groups of vitality change (upgraded, no change, and degraded) were identified for each individual, and its associations with the former ecological traits were examined using maximum likelihood analyses of variance. SAS Ver. 9.2 (2008) was used in all analyses.

\section{Spatial distribution}

In May 2011, we installed two quadrats in each habitat (Habitats I and II) for a total of four quadrats (each $50 \times$ $50 \mathrm{~m}$ ) (Fig. 1b). The GPS coordinates for 105 individuals within the quadrats were mapped using ArcMap Ver. 9.3 (Environmental Systems Research Institute 2008).

Male and female trees' spatial structures were analyzed two ways. First, the pattern of association between the nearest male and female neighbors was examined using Fisher's exact test. Second, the O-ring statistic suggested by Wiegand and Moloney (2004) was used. The O-ring statistic is useful for identifying the spatial correlation between populations. The value of $\mathrm{O}(\mathrm{r})$ was calculated as follows: around each individual data point, numerous circles with radius $r$ were drawn, and the correlation between the average number of individuals within the circles and the radius $r$ was deduced to determine the $\mathrm{O}$ value. To conduct significance tests on the $\mathrm{O}(\mathrm{r})$ value for each distance $r$, the null hypothesis was formed using complete spatial randomness (CRS). The $95 \%$ confidence interval was obtained after 999 times of randomization using Monte Carlo simulations for each population. If the $\mathrm{O}(\mathrm{r})$ value was above the CRS value, the individuals were considered clumped; if it was within the $95 \%$ confidence interval, they were considered randomly distributed; and if it was below the CRS value, they were considered regularly distributed. All calculations and simulations were performed using PROGRAMITA software (Wiegand 2010).

\section{RESULTS}

\section{Mean size and sex ratio of $T$. nucifera}

For the total of 2,861 trees measured in 2009, the mean dbh was $52.4 \pm 20.1 \mathrm{~cm}$ (mean $\pm \mathrm{SD}$ ) and the mean height was $10.4 \pm 2.2 \mathrm{~m}$ (Table 1). However, the mean dbh varied widely among plots, ranging from $39.4 \mathrm{~cm}$ (Plot 10) to 61.7 $\mathrm{cm}$ (Plot 5). The population density was 67.6 trees/ha, but this value also differed among plots. For example, Plots 1, 4, and 9 exhibited very low densities ( $<30$ trees/ha), whereas Plot 10, which was adjacent to Plots 1 and 9, exhibited the highest density (114 trees/ha). Across the ten plots, mean dbh values were independent of densities $(r=$ $0.23, P=0.5187, N=10$ ). Therefore, moving from Habitat I to Habitat III, there was a tendency for T. nucifera trees to decrease in size regardless of density changes.

The sex ratio of the trees was 0.52 in both 1999 and 2009. The null hypothesis of an equal sex ratio was rejected, revealing a significant bias for males (Table 2). However, significance in sex ratios was detected only in three plots with opposite patterns: there were 1.4-1.6× more males than females in Plots 3 and 5, while there were 2.8x more females than males in Plot 8 (Table 2). This plotbased pattern was observed at the habitat level as well: there were $1.5 \times$ more males than females in Habitat I but $1.2 \times$ more females than males in Habitat III. Habitat II showed a 1:1 ratio.

Sex ratios tended to change in a U-shape according to dbh class (Table 2). Small trees $<30 \mathrm{~cm}$ dbh and large trees $\geq 60 \mathrm{~cm}$ dbh exhibited significant male skews. In particular, trees with $<10 \mathrm{~cm}$ dbh and $\geq 100 \mathrm{~cm}$ dbh had sex ratios of 0.79 and 0.85 , respectively, indicating that the 


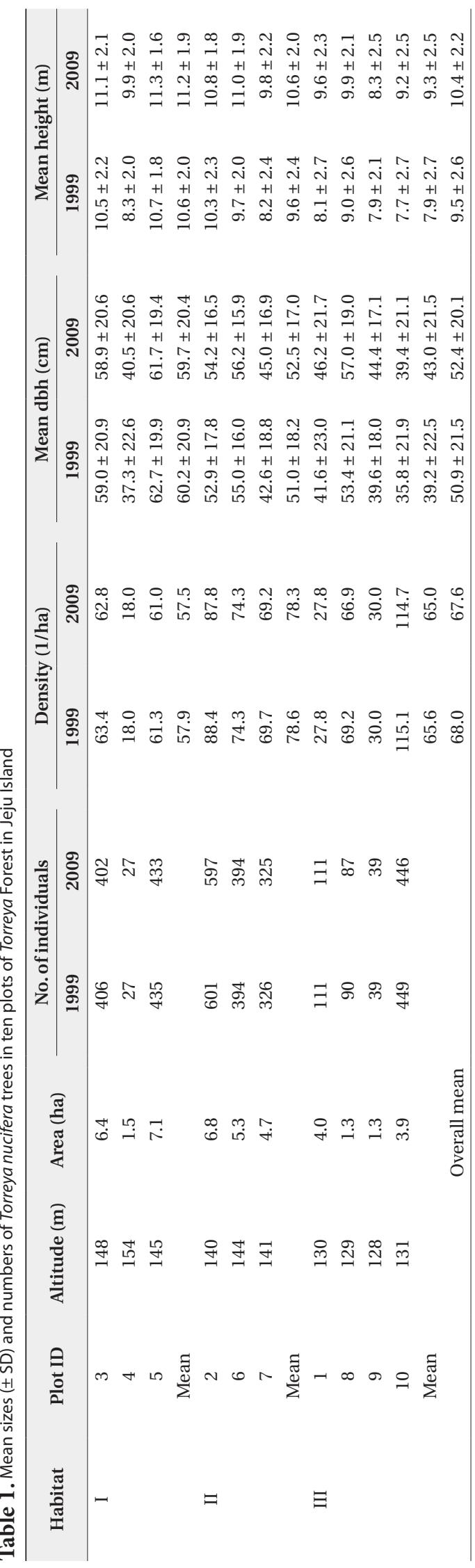

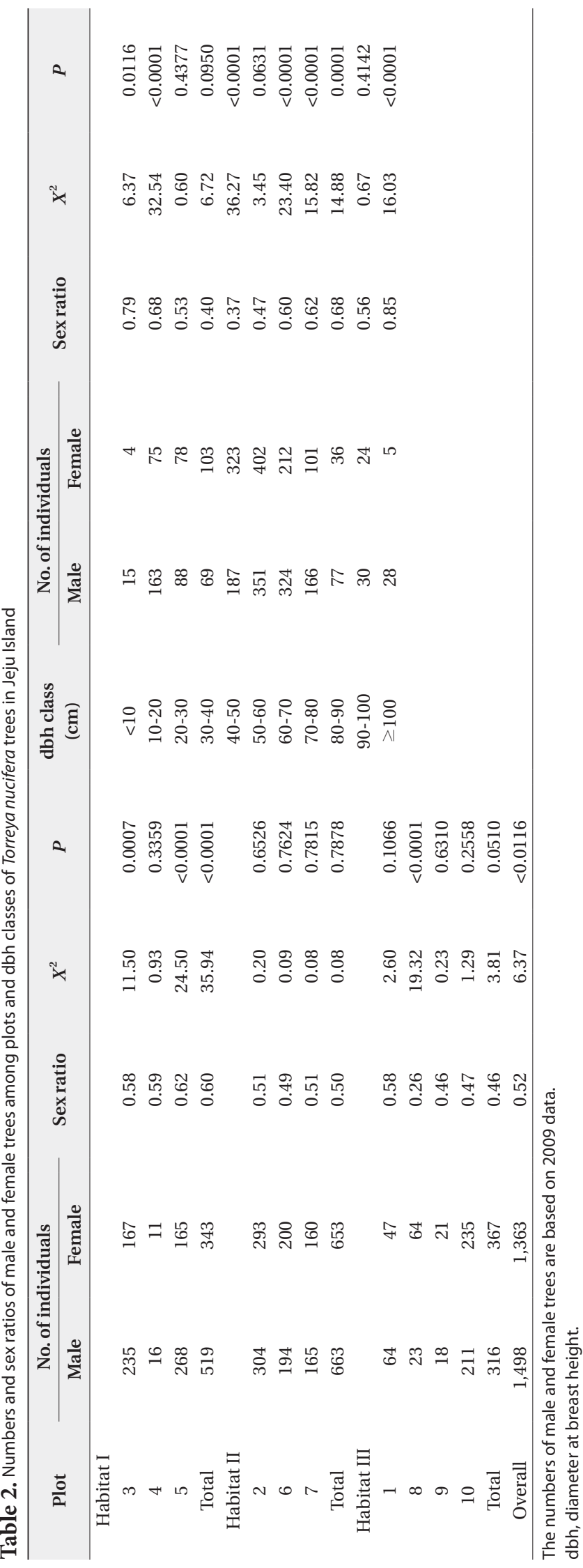


male trees were $3.8 \times$ and $5.6 \times$, respectively, more abundant than females. On the other hand, the sex ratio of a 40-50 $\mathrm{cm}$ dbh class was 0.37 , meaning that this size group is significantly skewed toward being female.

\section{Relationship among dbh, habitat, and sex}

One-way ANOVA using either sex or habitat as an independent variable showed that males had larger mean dbh than females by $2 \mathrm{~cm}$ (Table 3 ). The dbh also differed significantly among habitats, declining from Habitat I to Habitat III by an average of $17 \mathrm{~cm}$ (Table 3).

In two-way ANOVA using habitat and sex as independent variables, the habitat $\times$ sex interaction effect was significant (Table 3). Separate analyses for each habitat showed that in Habitats I and II, males were larger than females, while in Habitat III, the opposite pattern was observed. In subsequent analyses of each habitat, the relationship between dbh and sex differed among habitats. Across all plots in Habitat I, males were larger than females (plot, $F_{2,856}=15.19, P<0.0001$; sex, $F_{1,856}=12.73$, $P=0.0004$; plot $\times$ sex, $F_{2,856}=0.23, P=0.7978$ ). On the other hand, in Habitats II and III, there was a significant plot $\times$ sex interaction (Habitat II, plot, $F_{2,1310}=47,19, P<$ 0.0001 ; sex, $F_{1,1310}=1.38, P=0.2405$; plot $\times \operatorname{sex}, F_{2,1310}=6.43$, $P=0.0017$; Habitat III, plot, $F_{3,675}=17,82, P<0.0001$; sex, $F_{1,675}=2.15, P=0.1428$; plot $\times$ sex, $F_{3,675}=2.82, P=0.0383$ ). A significant difference in mean dbh between male and female trees was detected only in Plot 2 (Habitat II) and Plot 10 (Habitat III) (Fig. 2). However, females were larger

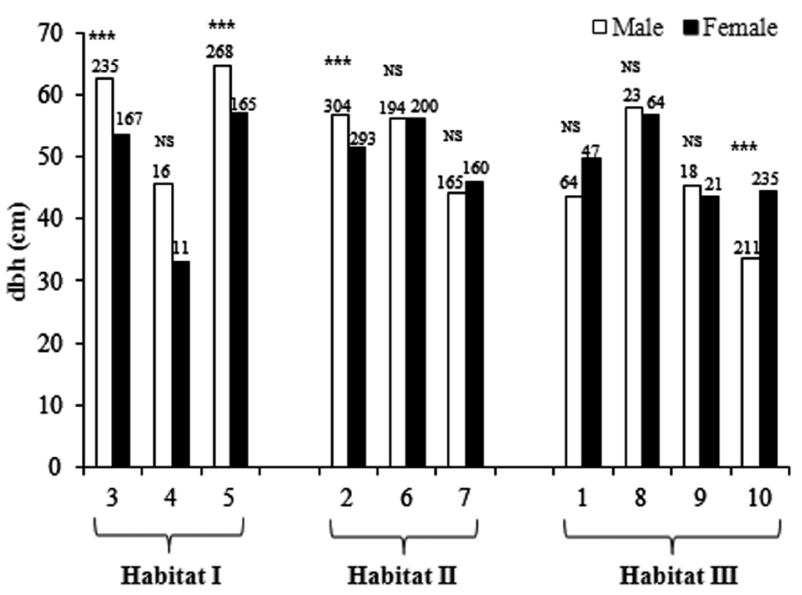

Fig. 2. Relationship between the plot and mean diameter at breast height (dbh) of male and female trees. Numbers on the bar represent the number of male and female trees. One-way ANOVA regarding the effect of sex was conducted for each plot. NS, not significant. ${ }^{* * * *} P<0.001$.

in Plot 2, while males were larger in Plot 10.

In two-way ANOVA examining the difference in annual dbh growth rates between habitat and sex, significant results were detected only when annual growth rates were expanded up to $3 \mathrm{~mm}\left(\leq 1 \mathrm{~mm}, F_{5,309}=1.01, P=\right.$ $0.4104 ; \leq 2 \mathrm{~mm}, F_{5,643}=1.18, P=0.3185 ; \leq 3 \mathrm{~mm}, F_{5,949}=3.88$, $P=0.0018)$

\section{Relationship between tree vitality and tending}

In 1999, vitality was significantly associated with climb-

Table 3. One-way ANOVA of the effect of habitat and sex and two-way ANOVA of the effects of habitat and sex on diameter at breast height of Torreya nucifera

\begin{tabular}{|c|c|c|c|c|c|c|c|}
\hline Source of variation & df & $F$ & $P$ & $\begin{array}{c}\text { Categories of } \\
\text { habitat and sex }\end{array}$ & $\overline{\mathrm{X}}(\mathrm{cm})$ & SD & $N$ \\
\hline \multicolumn{8}{|l|}{ One-way ANOVA } \\
\hline \multirow[t]{3}{*}{ Habitat } & 2,2858 & 144.67 & $<0.0001$ & Habitat I & $59.73 \mathrm{~A}$ & 20.35 & 862 \\
\hline & & & & Habitat II & $52.52 \mathrm{~B}$ & 16.96 & 1,316 \\
\hline & & & & Habitat III & $43.03 \mathrm{C}$ & 21.50 & 683 \\
\hline \multirow[t]{2}{*}{ Sex } & 1,2859 & 10.15 & 0.0015 & Male & $53.57 \mathrm{~A}$ & 22.34 & 1,498 \\
\hline & & & & Female & $51.18 \mathrm{~B}$ & 17.25 & 1,363 \\
\hline \multicolumn{8}{|l|}{ Two-way ANOVA } \\
\hline Habitat & 2 & 137.28 & $<0.0001$ & & & & \\
\hline Sex & 1 & 0.34 & 0.5627 & & & & \\
\hline Habitat $\times$ sex & 2 & 41.10 & $<0.0001$ & & & & \\
\hline Model & 5,2855 & 76.51 & $<0.0001$ & & & & \\
\hline
\end{tabular}

Multiple range tests were conducted following the one-way ANOVA. Different letters among categories of habitat and sex are used to indicate significant differences between means at the $a=0.05$ level. 
er coverage only in both male and female trees $(r=0.56$ for both male and female trees; $N=1,498$ and 1,371, respectively) and not with any other examined traits. Excluding the association between areas of bark holes and stripped barks, correlations between ecological traits were either weak or absent.

In 1999, trees assigned to the healthy group comprised only one third of the population $(36.4 \%, 42.5 \%, 19.3 \%$, and $1.8 \%$ for healthy, medium, weak, and very weak, respectively). In two-way contingency table analyses, vitality was significantly associated with dbh, habitat, and sex (Table 4). Almost half of the large trees $\geq 60 \mathrm{~cm} \mathrm{dbh}$ $(48.5 \%)$ were identified as healthy, and $12.8 \%$ of them were identified as weak or very weak. On the other hand, medium-sized trees (30-60 cm dbh) (26.9\%) rather than small trees $<30 \mathrm{~cm}$ dbh were mainly identified as being weak or very weak. The proportion of weak and very weak trees was $27.6 \%$ in Habitat I, while it was lower in Habitats II and III (18.2\% and 18.5\%, respectively). Conversely, the proportion of healthy trees in Habitat III was 1.6× greater than in Habitat I. The probability of males being healthy was 1.2 times higher than that of females (39.3\% vs. $33.2 \%$ for male and female trees, respectively). The two groups of plots that were assigned to tending or not in 1999 did not differ in vitality before the tending was initiated (Table 4).

After ten-year tending, the proportion of trees identified as healthy in 2009 increased $1.9 \times$ compared to that of 1999 (69.7\%, 21.9\%, 6.6\%, and 1.8\%, for healthy, medium, weak, and very weak, respectively). Vitality in 2009 was significantly associated with dbh, habitat and tending but not with sex (Table 4). Healthy trees were twice more abundant among large trees than small trees (88.9\% vs. $43.0 \%$ ). Conversely, weak (and very weak) trees were almost ten times more abundant in small trees than in large trees $(20.3 \%$ vs. $2.3 \%)$. In Habitat I, the number of trees showing moderate vitality was less than expected, while in Habitat III, the reverse was true. In particular, the association between vitality and tending was quite strong

Table 4. Two-way contingency table of vitality vs. dbh, habitat, sex, and management among Torreya nucifera trees in 1999 and 2009

\begin{tabular}{|c|c|c|c|c|c|c|c|c|c|c|c|}
\hline & \multicolumn{4}{|c|}{1999 Vitality } & \multicolumn{4}{|c|}{2009 Vitality } & \multicolumn{3}{|c|}{ Vitality change } \\
\hline & $\mathbf{H}$ & M & W & Vw & $\mathbf{H}$ & M & W & Vw & Upgraded & No change & Degraded \\
\hline \multicolumn{12}{|l|}{$\mathrm{dbh}$} \\
\hline$<30 \mathrm{~cm}$ & 165 & 159 & 80 & 10 & $178-$ & $152+$ & $63+$ & $21+$ & $125-$ & 182 & $107+$ \\
\hline $30-60 \mathrm{~cm}$ & $378-$ & $654+$ & $346+$ & 34 & 903- & $377+$ & 107 & 25 & $747+$ & $546-$ & 119 \\
\hline \multirow[t]{2}{*}{$\geq 60 \mathrm{~cm}$} & $483+$ & 386 & $119-$ & 8- & $885+$ & 89- & $17-$ & $5-$ & 455 & $505+$ & $36-$ \\
\hline & \multicolumn{4}{|c|}{$\mathrm{G}=147.82, P<0.0001$} & \multicolumn{4}{|c|}{$\mathrm{G}=368.03, P<0.0001$} & \multicolumn{3}{|c|}{$\mathrm{G}=186.24, P<0.0001$} \\
\hline \multicolumn{12}{|l|}{ Habitat } \\
\hline Habitat I & $234-$ & 390 & $208+$ & $30+$ & 631 & $156-$ & 67 & $8(-)$ & $496+$ & $313-$ & $53-$ \\
\hline Habitat II & 520 & 556 & 226 & $14-$ & 903 & 299 & 86 & 28 & $573(-)$ & 600 & $143(+)$ \\
\hline \multirow[t]{2}{*}{ Habitat III } & $272+$ & 253 & 111 & 8 & 432 & $163(+)$ & 34 & 15 & $258-$ & $320+$ & 66 \\
\hline & \multicolumn{4}{|c|}{$\mathrm{G}=65.30, P<0.0001$} & \multicolumn{4}{|c|}{$\mathrm{G}=21.68, P=0.0014$} & \multicolumn{3}{|c|}{$\mathrm{G}=61.31, P<0.0001$} \\
\hline \multicolumn{12}{|l|}{ Sex } \\
\hline Male & $581(+)$ & 602 & 272 & 25 & 1,055 & 303 & 93 & 29 & 664 & 683 & 133 \\
\hline \multirow[t]{2}{*}{ Female } & $445(-)$ & 597 & 273 & 27 & 911 & 315 & 94 & 22 & 663 & 550 & 129 \\
\hline & \multicolumn{4}{|c|}{$\mathrm{G}=11.43, P=0.0096$} & \multicolumn{4}{|c|}{$\mathrm{G}=5.01, P=0.1712$} & \multicolumn{3}{|c|}{$\mathrm{G}=7.69, P=0.0214$} \\
\hline \multicolumn{12}{|l|}{ Management } \\
\hline Tending & 1,026 & 1,199 & 545 & 52 & 1,966 & 618 & 187 & 51 & 1,327 & 1,233 & 262 \\
\hline \multirow[t]{2}{*}{ No tending } & 16 & 11 & 12 & 0 & $2-$ & 12 & $14+$ & $11+$ & $1-$ & 14 & $24+$ \\
\hline & \multicolumn{4}{|c|}{$\mathrm{G}=5.96, P=0.1138$} & \multicolumn{4}{|c|}{$\mathrm{G}=102.55, P<0.0001$} & \multicolumn{3}{|c|}{$\mathrm{G}=77.71, P<0.0001$} \\
\hline
\end{tabular}

The likelihood ratio chi-square $(G)$ is reported for each table. Vitality change for each tree between 1999 and 2009 was classified into three categories: upgraded, no change, and degraded.

Vitality: $\mathrm{H}$, healthy; $M$, moderate; $W$, weak; $V W$, very weak. $A+/$ - sign indicates the observed values were greater or less than the expected values at the $\alpha=0.05$ level and (+/-) at the $\alpha=0.1$ level.

$\mathrm{dbh}$, diameter at breast height. 
after ten-year tending (Table 4). Seventy percent of the trees in the tending plots were healthy compared to $5.1 \%$ in the non-tended plot.

Tracking the individual tree vitality for ten years, the proportion of trees whose vitality was upgraded, maintained or degraded was $46.4 \%, 43.6 \%$, and $10.0 \%$, respectively (Table 4). Vitality change patterns differed significantly according to dbh, habitat, and sex. Almost half of the medium-sized trees displayed improved vitality $(52.9 \%)$, while only $8.4 \%$ of them displayed decreased vitality. In contrast, only one third of small trees exhibited increased vitality, while one fourth displayed decreased vitality ( $30.2 \%$ vs. $25.9 \%$ ). Compared to Habitat III, Habitat I trees had a $1.4 \times$ higher probability of having an upgraded vitality. Among females, the proportion of trees whose vitality was upgraded was greater than those with no change $(49.4 \%$ vs. $41.0 \%)$, whereas the opposite was true for males ( $44.9 \%$ vs. $46.2 \%$ ). Also, approximately half $(47.0 \%)$ of the trees in the tended plots for ten years had upgraded vitalities compared to those of the trees in the non-tended plot, and only 9.3\% had lower vitalities. In contrast, only a single tree from the non-tended plot displayed improved vitality, while $61.5 \%$ displayed worsened vitalities. Considering dbh, habitat, and sex simultaneously, all main variables and the $\mathrm{dbh} \times$ habitat interaction were significantly associated with vitality changes (Table 5). Separate analyses for each habitat showed that in all habitats, a vitality change was associated with dbh without significant two-way interactions between $\mathrm{dbh}$ and sex (Habitat I, G $=30.67, P<0.0001, N=862$; Habitat II, $\mathrm{G}=109.26, P<0.0001, N=1,316$; Habitat III, G =109.267,

Table 5. Maximum likelihood analysis of variance with vitality change as a response variable and dbh, habitat, and sex as explanatory variables $(N=2,822)$

\begin{tabular}{lccc}
\hline \multicolumn{1}{c}{ Source } & df & G & \multicolumn{1}{c}{$\boldsymbol{P}$} \\
\hline Intercept & 2 & 294.38 & $<0.0001$ \\
dbh & 4 & 153.30 & $<0.0001$ \\
Habitat & 4 & 32.50 & $<0.0001$ \\
Sex & 2 & 10.78 & 0.0046 \\
dbh $\times$ habitat & 8 & 17.20 & 0.0281 \\
dbh $\times$ sex & 4 & 3.43 & 0.4893 \\
Habitat $\times$ sex & 4 & 0.75 & 0.9447 \\
dbh $\times$ habitat $\times$ sex & 8 & 11.16 & 0.1928 \\
Likelihood ratio & & $\cdot$ & $\cdot$ \\
\hline
\end{tabular}

Only Torreya nucifera trees from tended plots were included in these analyses.

$\mathrm{dbh}$, diameter at breast height.
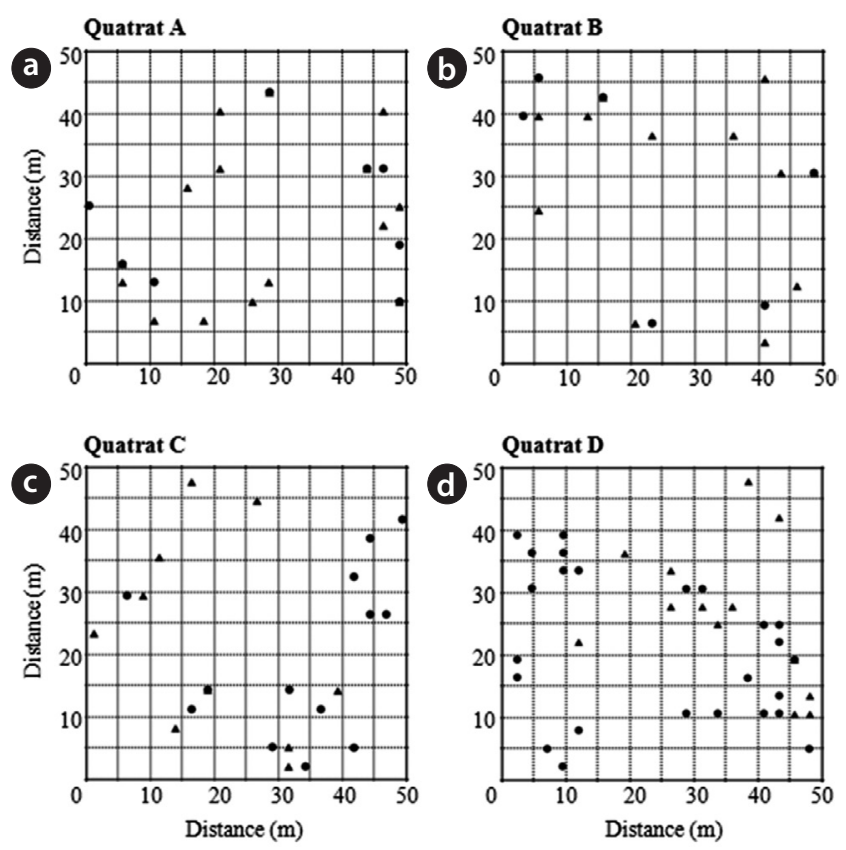

Fig. 3. Distribution of male $(\mathbf{\Delta})$ and female $(\bullet)$ Torreya nucifera in the four quadrats. (a) Quadrat A. (b) Quadrat B. (c) Quadrat C. (d) Quadrat D.

$P<0.0001, N=644 ; \mathrm{df}=4$ for all habitats), while in Habitat II it was also associated with sex (Habitat II, G = 7.32, $P=$ 0.0257, $\mathrm{df}=2$ ).

Of the 17 trees that died between 1999 and 2009, almost half were healthy $(N=8)$ and covered weakly with climbers $(N=10)$ in 1999 . However, due to a small number of dead trees, it was not possible to find a relationship between mortality and ecological factors, e.g., sex, climber coverage, and plot.

\section{Spatial pattern}

Fig. 3 shows the distribution pattern of male and female trees within four quadrats established in Habitats I and III. Sex ratios within quadrats were quite analogous to those within habitats $(0.65$ and 0.63 , respectively, in quadrats A and B in Habitat I; 0.43 and 0.35 , respectively, in quadrats $\mathrm{C}$ and D in Habitat III). Significant associations between nearest neighbor sexes were detected only in quadrats $B$ and D (A, $X^{2}=0.02, P=0.33$; B, $X^{2}=8.06, P=0.0065$; C, $\left.X^{2}=0.21, P=0.3062 ; \mathrm{D}, X^{2}=9.49, P=0.0034\right)$. However, due to a lack of consistent patterns in significance across quadrats, it was difficult to interpret these results. Based on the O-ring statistic, there was no significant spatial pattern in any of the quadrats (Fig. 4). Only in quadrat D was there a weak pattern of clumping among females at a distance of $r=7$ : however, the pattern did not persist. 

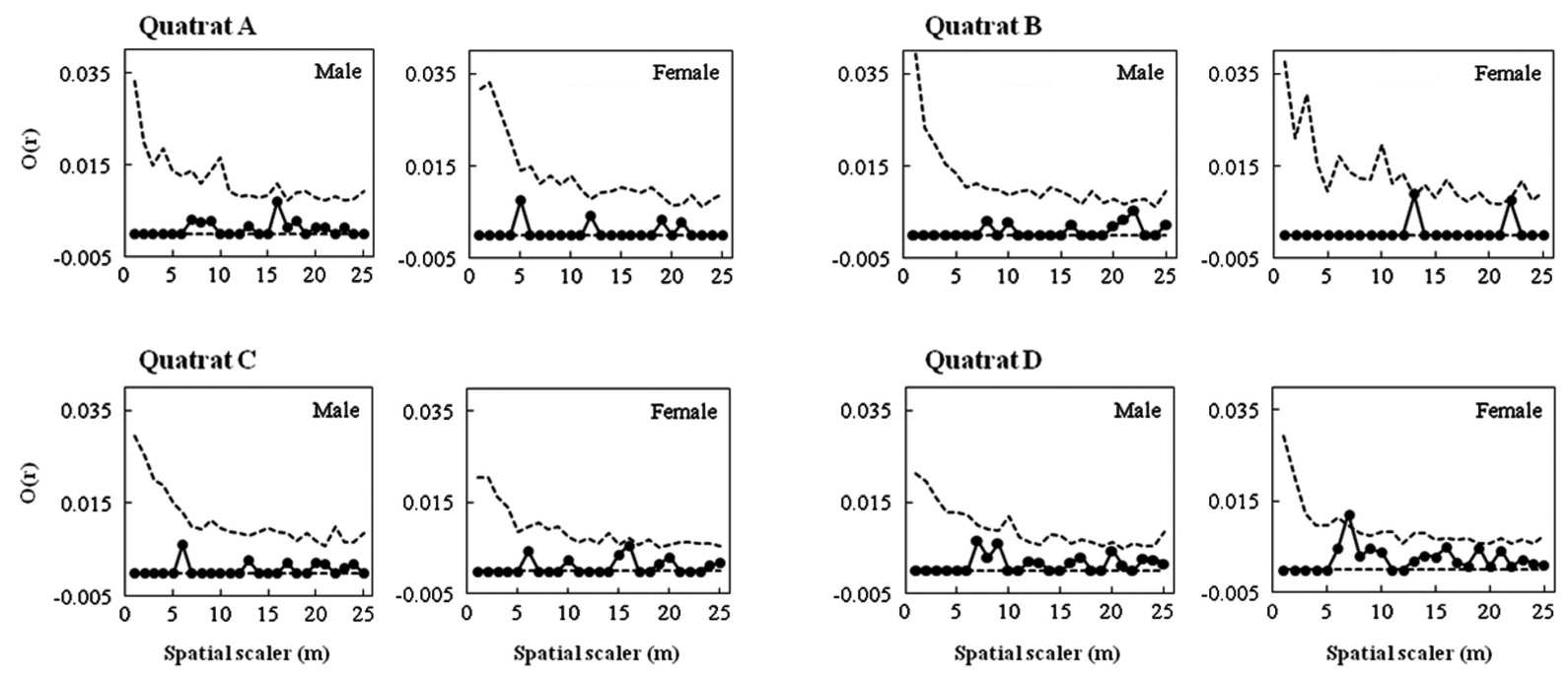

Fig. 4. Spatial analysis of male and female Torreya nucifera in four quadrats, $A, B, C$, and D. Filled circles indicate the mean $O(r)$ for an annulus of radius $r$ with 1-m lags. Dashed lines indicate confidence envelopes regarding the random spatial structure null hypothesis.

\section{DISCUSSION}

\section{Sex ratios}

Until quite recently, the sex ratios of T. nucifera trees in Jeju Island have been assumed equal (1:1) (KTHA 1999, Lee 2009). In this study, we found that Torreya Forest has a sex ratio of 0.52 (1,498 males and 1,363 females) that is significantly male-biased. This result corresponds to those of earlier studies that show male-biased sex ratios in many dioecious woody species (Lloyd 1973, Opler and Bawa 1978, Ornduff 1985, Thomas and LaFrankie 1993, Obeso et al. 1998).

However, sex ratios of $T$. nucifera trees vary according to the trees' dbh values and habitats. The sex ratio and dbh class are correlated not in a simple pattern but rather in a complex U-shape pattern: male bias among trees with $\mathrm{dbh}<30 \mathrm{~cm}$ and $\geq 60 \mathrm{~cm}$, and female bias between the two groups. Analogous patterns were observed in Acer negundo (Jing and Coley 1990), Siparuna grandiflora (Nicotra 1998), and Salix sachalinensis (Ueno et al. 2007). Male-biased sex ratios in relatively small trees are likely to be a result of male trees' precocious growth compared to that of female trees. Male trees may attain $\mathrm{dbh} \geq 6 \mathrm{~cm}$ earlier than females, consequently contributing to the higher sex ratio in small trees. Woody plants in general possess a lower mortality than herbs and often choose to hold off on reproductive activities rather than die in unfavorable conditions, potentially resulting in ambiguous sex-based mortality patterns (Nicotra 1998). Despite this, the results that males were $6 \times$ more abundant than females for trees with $\mathrm{dbh} \geq 100 \mathrm{~cm}$ strongly suggest a higher mortality for females due to their high reproductive costs.

On the other hand, a higher proportion of female trees among the middle-sized trees may reflect the increase in female trees that have grown as much as males (reaching 30-60 cm dbh) until they become old. In this study, we could not find evidence of differences between sexes in annual dbh growth, although average male dbh was slightly larger than that of females. However, it should be mentioned that in 1999, measuring dbh was an extremely difficult task because of climbers' heavy coverage of trunks at that time. Lee (2009) noted that the dbh of $T$. nucifera trees increases by an average of $1 \mathrm{~mm}$ per year or $10 \mathrm{~mm}$ over ten years but did not consider sex-specific $\mathrm{dbh}$ growth. Close examination of dbh growth needs to be studied to incorporate microhabitats, sex, and life history stages.

As the distance from the Dotoreum increased, and the elevation decreased, the sex ratios of T. nucifera trees declined from 0.60 in the upper terrain (Habitat I) to 0.46 in the lower terrain (Habitat III). Thus, the sex ratio and dbh gradients appear to be relatively concordant with the elevation gradient. Whether the elevation gradient represents a certain environmental factor that can affect resource availability, e.g., light, soil moisture, or temperature, has not been examined in this study: such information is critical in understanding factors affecting $T$. nucifera's sex ratios. Although there are opposing views, this forest is generally believed to have generated naturally (Kim 1985, Shin et al. 2010). However, several plots deviate quite a bit from the overall size or density pattern. 
For example, Plot 10 consisted of smaller trees than plots within the same habitat, but its density was twice as high as the average population density of 67.6 trees/ha. Plot 4 was also characterized by much smaller trees than nearby plots. A photo taken in 1967 showed that these plots were much thinner in the past (unpublished data). Thus, considering the long history of this forest and economic values of T. nucifera, it is difficult to believe that the forest is entirely natural. Understanding the patchy structures described above would provide valuable information for the adaptive conservation of $T$. nucifera trees in Jeju Island.

\section{Tree vitality}

Diverse climbers such as Kadsura japonica, Parthenocissus tricuspidata, Hedera rhombea, Euonymus fortunei, Smilax china, Pueraria lobata, and Trichosanthes kirilowii inhabit Torreya Forest (Lee 2009). The negative effects of climbers on host plants, e.g., exerting pressure to the trunk and reducing host plant photosynthesis, are widely known (Tibbetts and Ewers 2000). The strongly negative correlations between trees' vitalities and climber coverage confirms the negative effects of climbers in T. nucifera. In Torreya Forest, ten years of tending increased the proportion of healthy trees from $40 \%$ in 1999 to $70 \%$ in 2009 . On the other hand, in the plot that was not tended, only a single tree (equal to $5 \%$ in proportion) was in a healthy condition, while $61.5 \%$ were in weak condition. These results reveal that suppression by climbers can be detrimental to T. nucifera. T. nucifera is an extremely shade-tolerant species (KTHA 1999), and climbers are generally known to be more pronounced on shade-tolerant host species (Schnitzer and Bongers 2002).

The effect of tending on T. nucifera's vitality can be age, habitat, and sex dependent. In contrast to $53 \%$ of medium-sized trees enhancing their vitality by 2009 , a large portion of small trees' vitality declined sharply during the same time. This suggests that tending effects are sizedifferential: through tending, medium-sized trees seem better able to recover their competitive ability than smallsized trees. The lower fitness of small trees after tending can imply a serious problem of securing successive trees especially because seedlings and saplings are rare in the forest. Tending effects also differed among habitats. Habitat I was characterized by large trees with wider crowns and seemed to have had more time to be colonized by the climbers. However, the significant $\mathrm{dbh} \times$ habitat interaction during the simultaneous association tests of vitality change, dbh, habitat, and sex, suggests that the association of vitality and dbh can vary among habitats. Malizia and Grau (2006) also showed that liana colonization in a subtropical montane forest was not a function of tree size but was rather largely a function of light and canopy access through dispersal at a scale of up to $40 \mathrm{~m}$. It is notable that males and females did not show vitality differences in 2009, suggesting that climber removal may provide more benefits to females that suffer from resource limitation. This result is likely to reflect indirect evidence of female reproductive costs.

Tending may be needed to maintain T. nucifera trees for a sustainable period. However, tending actions are necessarily accompanied by disturbance, changing species composition, and/or nutrient dynamics (Schnitzer and Bongers 2002). Recent reports that Pinus thunbergii and several broadleaved trees are increasing, and that exotic species such as Zingiber mioga are expanding its range in the forest (Lee 2009) may be related to tending or other human activities in the forest. If so, tending or managing Torreya Forest should consider the ecology of trees such as size, age, habitat, and sex rather than implementing strict and uniform actions across the entire forest. Maintaining the ecosystem integrity may be the ultimate goal of conservation.

\section{Spatial pattern of $T$. nucifera trees}

The expected SSS under the hypothesis of the high reproductive cost of females has been observed in many angiosperms and gymnosperms including Juniperus virginiana (Lawton and Cothran 2000) and Taxus baccata (Hultine et al. 2007). However, in this study, we did not find a significant pattern of spatial structure, similar to other more recent studies (Ueno et al. 2007, Schmidt 2008, Gao et al. 2009, Forero-Montaña et al. 2010). Male and female T. nucifera were distributed randomly in all quadrats except $\mathrm{D}$, in which a weak pattern of female clumping could be observed at a distance of $r=7 \mathrm{~m}$. Nonetheless, we acknowledge that this study has limitations, largely due to the following reasons. First, as most of trees in the forest are $>200$ years old and their crown width is very large, there were limited numbers of trees within the quadrats, which possibly reduced the power of the spatial analysis. Second, Torreya Forest represents a Gotjawal forest on rocky ground with thin soil and broken lava blocks, creating extremely heterogeneous microhabitats (Song et al. 2007). Such forest heterogeneity may hinder the quadrat-based SSS. Furthermore, if trees respond to multiple stressors in such a heterogeneous habitat, it may not be possible to identify a clear SSS pattern. These possibilities should be addressed in a subsequent study. 


\section{ACKNOWLEDGMENTS}

We thank the World Natural Heritage Site Conservation Commission of Jeju Province for granting us permission to work in Torreya Forest. Dr. S. G. Lee provided invaluable ideas and help with this project and the field work; Dr. J-H. Kim gave information on Gotjawal and helped with the field work. Spatial analysis was possible with the help of Drs. M. G. Chung and M. Y. Chung.

\section{LITERATURE CITED}

Allen GA, Antos JA. 1993. Sex ratio variation in the dioecious shrub Oemleria cerasiformis. Am Nat 141: 537-553.

Armstrong JE, Irvine AK. 1989. Flowering, sex ratios, pollenovule ratios, fruit set, and reproductive effort of a dioecious tree, Myristica insipida (Myristicaceae), in two different rain forest communities. Am J Bot 76: 74-85.

Barrett SCH, Yakimowski SB, Field DL, Pickup M. 2010. Ecological genetics of sex ratios in plant populations. Philos Trans R Soc B Biol Sci 365: 2549-2557.

Bawa KS, Opler PA. 1977. Spatial relationships between staminate and pistillate plants of dioecious tropical forest trees. Evolution 31: 64-68.

Bierzychudek P, Eckhart V. 1988. Spatial segregation of the sexes of dioecious plants. Am Nat 132: 34-43.

Bukjeju-gun. 1971. Survey of Torreya Forest. Bukjeju-gun, Jeju. (in Korean)

Crawford RMM, Balfour J. 1990. Female-biased sex ratios and differential growth in arctic willows. Flora 184: 291302.

Dawson TE, Bliss LC. 1989. Patterns of water use and the tissue water relations in the dioecious shrub, Salix arctica: the physiological basis for habitat partitioning between the sexes. Oecologia 79: 332-343.

Donoghue MJ, Bell CD, Li J. 2001. Phylogenetic patterns in Northern Hemisphere plant geography. Int J Plant Sci 162(6 Suppl): S41-S52.

Environmental Systems Research Institute. 2008. Arc/Info User's Guide. Ver. 9.3. Environmental Systems Research Institute, Redlands, CA.

Fisher RA. 1930. The Genetical Theory of Natural Selection. Dover, New York.

Forero-Montaña J, Zimmerman JK, Thompson J. 2010. Population structure, growth rates and spatial distribution of two dioecious tree species in a wet forest in Puerto Rico. J Trop Ecol 26: 433-443.

Freeman DC, Klikoff LG, Harper KT. 1976. Differential resource utilization by the sexes of dioecious plants. Sci- ence 193: 597-599.

Gao P, Kang M, Wang J, Ye Q, Huang H. 2009. Neither biased sex ratio nor spatial segregation of the sexes in the subtropical dioecious tree Eurycorymbus cavaleriei (Sapindaceae). J Integr Plant Biol 51: 604-613.

Grant MC, Mitton JB. 1979. Elevational gradients in adult sex ratios and sexual differentiation in vegetative growth rates in Populus tremuloides Michx. Evolution 33: 914918.

Hong YP, Cho KJ, Kim YY, Shin EM, Pyo SK. 2000. Diversity of ISSR variants in the populations of Torreya nucifera. J Korean For Soc 89: 167-172.

Houle G, Duchesne M. 1999. The spatial pattern of a Juniperus communis var. depressa population on a continental dune in subarctic Québec, Canada. Can J For Res 29: 446-450.

Hultine KR, Bush SE, West AG, Ehleringer JR. 2007. Population structure, physiology and ecohydrological impacts of dioecious riparian tree species of western North America. Oecologia 154: 85-93.

Jing SW, Coley PD. 1990. Dioecy and herbivory: the effect of growth rate on plant defense in Acer negundo. Oikos 58: 369-377.

Kang H. 1993. Genetic effects on seed and seedling traits of Japanese nutmeg (Torreya nucifera S.) in Cheju Island. I. Variation in seed weight. Bull KACN Ser 12: 51-60.

Kim YD, Kwon YC. 1989. Cytogenetic and physiological studies in natural populations of Torreya nucifera. J Korean For Soc 78: 42-54. (in Korean)

Kim YS. 1985. Phytogeographic distribution of genus Torreya of the world. J Resour Dev 4: 143-150.

Korea Meteorological Administration. 2011. Climatological Normals of Korea (2001-2010). Korea Metropolitan Administration, Seoul. (in Korean)

Korea Tree Health Association (KTHA). 1999. Torreya nucifera Forest in Gujwa-eup: Conservation and Maintenance Measures. Bukjeju-gun, Jeju. (in Korean)

Lawton RO, Cothran P. 2000. Factors influencing reproductive activity of Juniperus virginiana in the Tennessee Valley. J Torrey Bot Soc 127: 271-279.

Lee SG. 2005. Genetic conservation strategy in the natural population of Torreya nucifera in Kujwa-eup, Cheju, Korea. MS Thesis. Sangji University, Wonju, Korea. (in Korean)

Lee SG. 2009. Studies on the biota, growth characteristics, and vegetational changes in relation to tending care intensity and conservation measures of the Torreya $\mathrm{nu}$ cifera Forest in Gujwa-eup, Jeju, Korea. PhD Dissertation. Sangji University, Wonju, Korea. (in Korean)

Lee TB. 2003. Coloured Flora of Korea. Hyangmoonsa, Seoul, 
p 128. (in Korean)

Lloyd DG. 1973. Sex ratios in sexually dimorphic Umbelliferae. Heredity 31: 239-249.

Lloyd D, Webb CJ. 1977. Secondary sex characters in plants. Bot Rev 43: 177-216.

Malizia A, Grau HR. 2006. Liana-host tree associations in a subtropical montane forest of north-western Argentina. J Trop Ecol 22: 331-339.

Milne RI, Abbott RJ. 2002. The origin and evolution of tertiary relict floras. Adv Bot Res 38: 281-314.

Nicotra AB. 1998. Sex ratio variation and spatial distribution of Siparuna grandiflora, a tropical dioecious shrub. Oecologia 115: 102-113.

Nuñez CI, Nuñez MA, Kitzberger T. 2008. Sex-related spatial segregation and growth in a dioecious conifer along environmental gradients in northwestern Patagonia. Ecoscience 15: 73-80.

Obeso JR, Alvarez-Santullano M, Retuerto R. 1998. Sex ratios, size distributions, and sexual dimorphism in the dioecious tree Ilex aquifolium (Aquifoliaceae). Am J Bot 85: 1602-1608.

Opler PA, Bawa KS. 1978. Sex ratios in tropical forest trees. Evolution 32: 812-821.

Ornduff R. 1985. Male-biased sex ratios in the cycad Macrozamia riedlei (Zamiaceae). Bull Torrey Bot Club 112: 393-397.

Ortiz PL, Arista M, Talavera S. 1998. Low reproductive success in two subspecies of Juniperus oxycedrus L. Int J Plant Sci 159: 843-847.

Ortiz PL, Arista M, Talavera S. 2002. Sex ratio and reproductive effort in the dioecious Juniperus communis subsp. alpina (Suter) Čelak. (Cupressaceae) along an altitudinal gradient. Ann Bot 89: 205-211.

Osunkoya OO. 1999. Population structure and breeding biology in relation to conservation in the dioecious Gardenia actinocarpa (Rubiaceae): a rare shrub of North Queensland rainforest. Biol Conserv 88: 347-359.

Queenborough SA, Burslem DFRP, Garwood NC, Valencia R. 2007. Determinants of biased sex ratios and inter-sex costs of reproduction in dioecious tropical forest trees.
Am J Bot 94: 67-78.

Renner SS, Ricklefs RE. 1995. Dioecy and its correlates in the flowering plants. Am J Bot 82: 596-606.

Sakai AK. 1990. Sex ratios of red maple (Acer rubrum) populations in northern lower Michigan. Ecology 71: 571-580.

SAS. 2008. SAS/STAT Software. Ver. 9.2. SAS Institute, Cary, NC.

Schmidt JP. 2008. Sex ratio and spatial pattern of males and females in the dioecious sandhill shrub, Ceratiola ericoides ericoides (Empetraceae) Michx. Plant Ecol 196: 281288.

Schnitzer SA, Bongers F. 2002. The ecology of lianas and their role in forests. Trends Ecol Evol 17: 223-230.

Shin HC, Lee GS, Park NC, Jung SY. 2010. Vegetation structure of the Torreya nucifera stand in Korea. J Korean For Soc 99: 312-322. (in Korean)

Song ST. 2000. Distributions and lithology of the aa rubble flows on Cheju Island, Korea. PhD Dissertation. Pusan National University, Busan, Korea. (in Korean)

Song ST, Kim HC, Kim DS, Yu SP, Jwa SH. 2007. Gotjawal of Jeju. The National Folk Museum of Korea, Seoul. (in Korean)

Thomas SC, LaFrankie JV. 1993. Sex, size, and interyear variation in flowering among dioecious trees of the Malayan rain forest. Ecology 74: 1529-1537.

Tibbetts TJ, Ewers FW. 2000. Root pressure and specific conductivity in temperate lianas: exotic Celastrus orbiculatus (Celastraceae) vs. native Vitis riparia (Vitaceae). Am J Bot 87: 1272-1278.

Ueno N, Suyama Y, Seiwa K. 2007. What makes the sex ratio female-biased in dioecious tree Salix sachalinensis? J Ecol 95: 951-959.

Wiegand T. 2010. Programita, a Software to Perform Point Pattern Analysis with Ripley's L and O-Ring Statistic. Department of Ecological Modelling, UFZ-Centre for Environmental Research, Leipzig.

Wiegand T, Moloney KA. 2004. Rings, circles, and null-models for point pattern analysis in ecology. Oikos 104: 209229. 